\title{
Should We Rethink How We Do Research?
}

\author{
Carlo Ghezzi
}

\begin{abstract}
Advances in digital technologies move incredibly fast from the research stage to practical use, and they generate radical changes in the world, affecting humans in all aspects of their life. The chapter illustrates how this can have profound implications on the way technological research is developed. It also discusses the need for researchers to engage more actively in public debates with society.
\end{abstract}

\section{Introduction: Coping with Disruptive Changes}

History shows that advances in science and technology have always produced changes in the world in which we live. With digital technologies, ${ }^{1}$ we experience unprecedented levels of change. They can affect human well-being, assist humans in their individual activities, and relieve them of strenuous or dangerous jobs. More broadly, they create an entirely new cyber-physical world in which they live and interact with natural phenomena, other individuals, and new kinds of artificial autonomous entities. The "old world," which was known to us for centuries, in which we felt comfortable and with which we slowly evolved, has been suddenly replaced by a new one whose laws we ignore and where humans may lose control. Digital humanism stresses that humankind must be at the center of innovation and technology has to serve society and the environment.

Technological developments are largely driven by research. To understand the lessons for research we can learn from the development of digital technologies, we need to reflect on its two key properties: radicality and speed of change.

The effects of digital technologies on humankind have indeed been revolutionary. Other radical shifts were generated by research in the past, but perhaps none is

\footnotetext{
${ }^{1}$ The umbrella term "digital technologies" includes both hardware and software (data, algorithms, AI).

C. Ghezzi $(\bowtie)$

Politecnico di Milano, Milano, Italy

e-mail: carlo.ghezzi@polimi.it
} 
affecting as profoundly every human life. For example, the shift from Ptolemaic astronomy - which considered the earth to be at the center of the universe with the sun, moon, and planets revolving around it - to the Copernican view had radical effects on science and philosophy but did not affect the individual's everyday life. Likewise, the radical shift in physics at the beginning of the twentieth century, caused by the developments of relativity theory and quantum mechanics, challenged the known view of the physical world, described by the axioms and laws of Newton's mechanics. This was a spectacular paradigm shift, which however had little effect on practically observable phenomena in everyday human life.

In addition, the transition of advances in digital technologies from the research stage into everyday life occurred much faster than for previous technologies. As observed, for example by Harari (2014), the Industrial Revolution, ignited by the invention of steam engines, took about two centuries to develop the modern industrial world. Digital technologies spread to the world in only a few decades, generating abrupt changes and hampering gradual and friction-less adaptation. ${ }^{2}$

\section{Effects on How We Do Research}

The main implication of speed of change is that scientists and engineers, ${ }^{3}$ in their exploratory work, cannot ignore the potential implications and effects of the new technology they develop. Delaying reflection on the use of technology to a later stage may cause serious harm. Alas, "later" is in fact "sooner" than expected; it can be too late! Rather, technological research must proceed hand-in-hand with the investigation of its implications. Traditionally, careful deployment strategies and trial usage of newly developed technology could prevent major damage, through adjustments and countermeasures. Today, however, radical innovations in image recognition based on AI deep learning techniques have been immediately transferred to practice without first exploring their limitations and potential implications. Adoption in law trials has raised serious ethical concerns and potential violations of human rights. Likewise, the advances that enabled mass mobile pervasive computing through personal devices and smartphones stressed mainly usability and functionality, at the expense of trustworthiness and dependability. As a result, infrastructures are open to all kinds of misuses and attacks, including privacy violations that led to serious political consequences. ${ }^{4}$ Plenty of examples of ethically sensitive technical issues are faced by current research on automatic vehicles.

\footnotetext{
${ }^{2}$ The digital revolution is also very fast and radically changing the way we do research, in almost all areas, through the unprecedented availability of data and the invention of algorithms which can manipulate them and reason about them, leading to discovery automation. The deep consequences of this change would require further discussion.

${ }^{3}$ In this chapter, the terms scientist and researcher are used interchangeably. Furthermore, they mainly refer implicitly to technological research.

${ }^{4}$ For example, the Pegasus spyware [https://en.wikipedia.org/wiki/Pegasus_(spyware)].
} 
The effect on humans and society of radical changes is a serious concern that must be addressed while developing technological research. To deal with it, research has to broaden its focus, moving beyond pure technical boundaries and bringing in a focus on the potential human and societal issues involved. This asks scientists to break the rigid silos into which research is currently compartmented. Philosophers and social scientists, for example, need to be integrated in research groups that develop new technology for autonomous vehicles; environmentalists, urban planners, and social scientists need to work with computer scientists to develop traffic management solutions in smart cities. The quest for interdisciplinarity-so far often more a fashionable slogan than reality-becomes a necessity. We seriously and urgently need to understand how this can be done. For example, how to achieve breadth without sacrificing depth of research, how to evaluate interdisciplinary work without penalizing it by applying traditional silo-based criteria, etc.

\section{Effects on Engagement with Society}

Speed and radicality of change have an important consequence on the need for scientists to engage with society. Traditionally, they interact and communicate almost exclusively with their silo peers. They are largely shielded from direct communication and interaction with a broader public. Limited forms of engagement include innovation initiatives, like generation of spin-offs and collaborations with industry, government, and policy makers. Fast and radical changes require more involvement, especially in discussing the potential developments and uses and raising broad social awareness. This, however, is easier said than done.

Researchers know well how to communicate with their peers. They learn how to do it since they enter a PhD program and continue to learn and improve throughout their career. Research is an intrinsically open process that relies on communication among peers. The main ambition of scientists is to achieve novel results and communicate them to the research community trough research papers, artifacts (such as data sets or software prototypes), and scientific debates in conferences. Their career progress largely depends on how successful they are in producing and spreading novel and relevant results to their peers. Ghezzi (2020) discusses the importance of communication among peers and also stresses the need for more neglected forms of public engagement, through which scientists lead, or participate in, scientific debates with a broader audience, outside the circle of peers: with government, policy and decision-makers, and the general public.

There are notable historical examples of scientists who engaged in public scientific debates, especially when progress led to radical changes. A famous case is Galileo Galilei, who strove to bring his support to the Copernican theory to the attention of the society of his time. He was well aware of the profound consequences of the shift from the Ptolemaic to the Copernican view: mankind was no more living at the center of the universe, but instead on a planet, which was just a small part of the solar system. He spoke to the informed society of his time through an essay, 
"Dialogue Concerning the Two Chief World Systems," in which a scientific conversation is carried on among three individuals: a Copernican scientist who explains the new theory to an educated citizen arguing against the statements made by a Ptolemaic scientist. Galileo is considered as the father of modern science. He taught to us that science is not blind faith on previous beliefs, dominant orthodoxy, or ideology. It relies on rational argumentations to arrive at whatever conclusions a careful analysis of evidence would suggest, even if they are not conformant with current beliefs. He developed new technology to empower humans to understand and dominate the physical world. His public engagement led him to confront the Catholic official doctrine, which followed the Ptolemaic view that the earth was at the center of the solar system. Galileo appeared before the Roman Inquisition and was eventually accused of heresy. He was forced to recant his views and sentenced to house arrest for the rest of his life.

Another example of a heated public debate occurred at the beginning of the twentieth century when the revolutionary developments in physics and mathematics by giants like Einstein, Plank, Bohr, and Hilbert brought together an outstanding group of physicists, philosophers, and mathematicians, who met in Vienna in a permanent seminar from 1924 until 1936, called Wiener Kreis (Vienna Circle). The members of the seminar aimed at founding philosophy on a modern scientific view of the world, keeping it separate from metaphysics.

Participants in the discussions included physicists, philosophers like Schlick (who chaired the group), Neurath, Popper, and Wittgenstein and mathematicians and logicians like Carnap and Gödel. The Vienna Circle dissolved in 1936, when Schlick died, and anti-semitism caused a diaspora of the other members. A fascinating account of this highly influential movement can be found in Sigmund (2017). More heated public discussions involved physicists at the end of World War II, when the relation between research and its direct use in the development of mass destruction weapons became evident. The debate was able to inform and involve both governments and citizens.

These examples of public involvement in scientific debates remained mostly at the level of "educated elites." The digital revolution is directly affecting every individual's life and requires a broader reach out. An informed debate needs to take place, involving not only scientists in almost all areas and decision-makers at all levels, but also citizens, to make sure that humans and the earth on which they live are at the center of technological developments.

\section{Conclusions}

Effective engagement with the general public requires that researchers learn how to communicate effectively and that their efforts in doing so are recognized and rewarded. They need to understand the role they must play in this conversation, which mainly aims at explaining the advances of research and pointing to the critical issues involved in its use, which may require collective, informed, rational decisions. 
The boundaries between scientific knowledge and personal opinions and beliefs should be kept clearly separate. Effective communication also demands a mature and competent audience. This raises serious concerns, since regrettably the level of scientific education has been decreasing in many countries. Even worse, paradoxically, in our highly technological world there is a widespread mistrust in sciencesee Nichols (2017) — which should be contrasted by more investments in education. In particular, we need to ensure that every responsible citizen understands how science and technology progress, how they can be trusted, and what their limits are. Development of an open space for discussions around digital technologies is crucial for the future of our democratic societies and realization of digital humanism.

\section{References}

Ghezzi, C. (2020) Being a Researcher: An Informatics Perspective. Springer International Publishing.

Harari, Y.N. (2014) Sapiens: A Brief History of Humankind. Random House.

Nichols, T. (2017) The Death of Expertise: The Campaign against Established Knowledge and Why it Matters. Oxford University Press.

Sigmund, K. (2017) Exact Thinking in Demented Times: The Vienna Circle and the Epic Quest for the Foundations of Science. Basic Books.

Open Access This chapter is licensed under the terms of the Creative Commons Attribution 4.0 International License (http://creativecommons.org/licenses/by/4.0/), which permits use, sharing, adaptation, distribution and reproduction in any medium or format, as long as you give appropriate credit to the original author(s) and the source, provide a link to the Creative Commons license and indicate if changes were made.

The images or other third party material in this chapter are included in the chapter's Creative Commons license, unless indicated otherwise in a credit line to the material. If material is not included in the chapter's Creative Commons license and your intended use is not permitted by statutory regulation or exceeds the permitted use, you will need to obtain permission directly from the copyright holder.

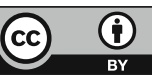

